\title{
Methods to Estimate Plant Available Water for Simulation Models
}

\author{
K.D. Behrman, M.L. Norfleet, and J. Williams
}

Kathrine D. Behrman, Research Agronomist, Grassland, Soil and Water Research Laboratory, USDA-ARS, Temple, TX, USA. Research Fellow, Department of Integrative Biology, University of Texas at Austin, Austin, TX, USA.

M. Lee Norfleet, Soil Scientist, USDA-NRCS, 808 East Blackland Rd., Temple, TX, USA.

Jimmy Williams, Senior Research Scientist, Texas A\&M AgriLife, 720 East Blackland Rd., Temple, TX, USA.

\begin{abstract}
Agricultural simulation models are increasingly being used in decision support tools at regional and national scales for crop production and water management. These models require hydrologic inputs; in particular plant available water $(P A W)$ is a critical parameter that helps determine if precipitation infiltrates and is stored as soil water, is lost directly to the atmosphere through soil evaporation, or is
\end{abstract}

1 
transported as groundwater flow. Accurate or realistic estimations of PAW for many geographic regions and soil types must be readily available as model input for simulating crop growth and many downstream processes, such as water quality, soil erosion, sediment loss, nutrient/pesticide fate and transport, and greenhouse gas emissions. In this study, we present a new algorithm for PAW estimation, termed the BNW algorithm, which was developed primarily based on principles of soil properties. The new BNW algorithm outperformed several commonly used algorithms for overall soil pedon fit and by USDA texture class. The BNW algorithm has the best fit and accuracy on sandy clay and sandy clay loam soils. Incorporation of the BNW algorithm into process based simulation models will improve the accuracy of crop production estimates and environmental impacts estimates at regional and national scales.

Keywords: Simulation modeling, spatial variation, soil water retention, texture, organic matter, bulk density. 


\section{Introduction}

Process based simulation models, such as ALMANAC, APEX, CROPSYST, DAYCENT, DSSAT, EPIC, and SWAT, are widely used to simulate plant growth (or crop yield), water quality, water erosion, sediment loss, nutrient/pesticide fate and transport, greenhouse gas emission, etc. (Arnold et al., 1998; Jones et al., 1998; Kiniry et al., 1992; Parton et al., 1998; Stockle et al., 1994; Williams et al, 1998; Williams et al., 1989). These models require inputs that describe dynamics related to soil water retention. Precipitation that infiltrates is stored as soil water, which can be extracted by plants and returned to the atmosphere by plant transpiration, lost directly to the atmosphere through soil evaporation, or transported as groundwater flow. Accurately estimating the quantity of stored soil water available for plant extraction is critical to simulate plant growth and soil water balance, which impact many downstream processes, such as water percolation, water runoff, sediment loss, nitrogen and phosphorous leaching, and soil organic carbon dynamics. These simulation models are increasingly being used at regional and national scales as decision support tools to help determine the impacts of conservation practices, best management practices, impact and feasibility of biofuel production, effects of climate change and land-use change, and state of water quality (Arnold et al., 2014; Behrman et al., 2013; Gelfand et al., 2013; Powers et al., 2011; Tuppad et al., 2010).

Plant available water (PAW) is defined as the volumetric water content a plant can extract $\left(\mathrm{m}^{3} \mathrm{H}_{2} \mathrm{O}\right.$ $\mathrm{m}^{-3}$ soil) from the soil. It is typically estimated as the difference between volumetric water content at the drained upper limit (field capacity) and lower limit (wilting point) of the soil. Field measurements of soil water retention are costly and time consuming (Ratliff et al., 1983; Ritchie et al., 1987). As a consequence, predictive functions have been developed to estimate PAW from commonly measured soil properties, such as particle size distribution, bulk density, and organic matter (Jagtap et al., 2004; Timlin et al., 1996).

In order to utilize simulation models to assess the impact of conservation practices on water 
management and crop production at large regional and watershed scales, it is critical to develop reliable estimates of PAW for many geographic regions and soil types. However, there is a lack of consensus regarding the most accurate method to estimate PAW, and large discrepancies have been observed depending on the region and input variables (Gijsman et al., 2002; Nemes et al., 2009; Wosten et al., 2001). Most PAW algorithms are fit by linear or non-linear parametric regression or non-parametric machine learning or clustering algorithms (Nemes et al., 2006; Rawls \& Brakensiek, 1989; Rawls et al., 1982; Saxton \& Rawls, 2006; Saxton et al., 1986; Schaap et al., 1998). Consensus on model fit is problematic because data used for model calibration is often not available and the algorithms are seldom refit as new data becomes available (Gijsman, et al., 2002).

In this study, we present a new approach to estimate PAW based on the theoretical water holding capacity and bulk density of soil particle size classes. This method is unique amongst most the other PAW algorithms because it is not a statistical fit or data mining algorithm that is dependent on the dataset used. It is named after the authors and termed the "BNW" algorithm. Next, we compare model fit to several commonly used predictive functions, including two linear regression techniques (Baumer \& Rice, 1988; Rawls, et al., 1982), one non-linear parametric regression method (Saxton \& Rawls, 2006), and one non-parametric method using a clustering algorithm based on nearest neighbors (Nemes, et al., 2006). This comparison demonstrates how the newly developed algorithm compares to other commonly used techniques, but is not intended to provide a comprehensive review or comparison of all possible methods. Lastly, we evaluate the ability of the all algorithms to predict PAW for a wide range of measured soils and USDA texture classes.

\section{Materials and Methods}

\section{Soil Dataset for Comparison}

Laboratory soil measurements from the United States Department of Agriculture (USDA) National Cooperative Soil Survey (NCSS) Soil Characterization Data were used to develop a test 
dataset to validate the new $\mathrm{BNW}$ algorithm and compare the $\mathrm{BNW}$ algorithm to several existing algorithms for a wide variety of agricultural soils (NCSS, 2005). The test dataset is composed of 1,852 complete pedons with 10,890 layers. The following criteria were designed to remove extreme data values not common on agricultural soils and soil pedons with incomplete records or incorrectly entered data values.

This analysis is limited to pedons that have or had agricultural tillage or disturbance as noted in the taxonomic description by the Ap designation. We excluded volcanic soils with orders Gelisols and Andisols or great/sub-groups Gypsic and Vitric. We also restricted this analysis to layers with bulk density between 0.8 and $2.0 \mathrm{~g} \mathrm{~m}^{-3}$, organic carbon less than 5.75 percent, and plant available water less than $0.3 \mathrm{~m}^{3} \mathrm{~m}^{-3}$. Values that are typical of agricultural soils.

Pedons were removed for when the following data values were missing. First, pedons were removed if they did not have at least two soil layers and if all layers were not present to $1 \mathrm{~m}$ depth or to bedrock. Second, each soil layer must have a data value for all eight required variables: plant available water (PAW), wilting point (WP), percent sand $(\mathrm{Sa})$, percent silt $(\mathrm{Si})$, percent clay $(\mathrm{Cl})$, percent organic carbon (OC), cation exchange capacity (CEC), and bulk density (Bd). As typical for mechanistic modeling, PAW $\left(\mathrm{m}^{3} \mathrm{~m}^{-3}\right)$ is defined as the volume of water released when the soil is dried from $1 / 3$ bar to 15 bars water tension (Richards \& Weaver, 1943). Wilting point (WP) by volume $\left(\mathrm{m}^{3}\right.$

$\left.\mathrm{m}^{-3}\right)$ is the measured gravimetric water content of 15 bar water tension on air-dry soil times Bd $\left(\mathrm{g} \mathrm{m}^{-3}\right)$. Field capacity (FC) is equal to the sum of WP and PAW. Last, incorrectly entered or unfeasible data values were removed. These include layers with the volume of water held at FC reported to be greater than porosity $(\mathrm{FC}>1-\mathrm{Bd} / 2.65)$ and values of $\mathrm{Sa}, \mathrm{Si}, \mathrm{OC}$, and $\mathrm{Bd}$ less than 0 .

\section{Development and Validation of the BNW Algorithm}

The $\mathrm{BNW}$ method was developed to estimate $P A W$ from equations derived to represent an optimum PAW $\left(P A W_{\mathrm{O}}\right)$ and optimum bulk density $\left(B d_{O}\right)$ based on percent sand $(S a)$, silt $(S i)$, clay $(C l)$, and organic matter $(O M)$. We used the conventional conversion factor that $O M$ equals 1.724 times 
organic carbon (van Bemmelen 1890). A coefficient was assigned to each particle class, and then a weighted average was used to calculate to $P A W_{\mathrm{O}}$ and $B d_{O}$. First, coefficients, $\alpha, \beta, \gamma, \delta$, were assigned to $\mathrm{Sa}, \mathrm{Si}, \mathrm{Cl}$, and $\mathrm{OM}$ respectively. The coefficients represent the hypothetical water holding capacity (volume of water in $\mathrm{m}^{3}$ per $\mathrm{m}^{3}$ of soil) of a theoretical soil composed of 100 percent $\mathrm{Sa}, \mathrm{Si}, \mathrm{Cl}$, or $\mathrm{OM}$. The values for each particle class were developed by calculating the PAW for horizons with greater than 85 percent $S a, 75$ percent $S i$, and 75 percent $C l$ and adjusting for the impact of the remaining particle class contribution. Organic matter was adjusted last using horizons with greater than 30 percent $O M$. The resulting equation for optimum plant available water, $P A W_{O}$, is

$$
P A W_{O}=\frac{\alpha S a+\beta S i+\gamma C l+\delta O M}{S a+S i+C l+O M}
$$

where $\alpha=0.05, \beta=0.26, \gamma=0.08$, and $\delta=0.9$.

Next, optimum bulk density $\left(B d_{O}\right)$ coefficients were assigned the minimum bulk density $\left(\mathrm{g} \mathrm{cm}^{-3}\right)$ for each particle class to maintain its structure as specified in the National Soil Survey Handbook (U.S. Department of Agriculture, 1995). The resulting optimum bulk density equation is

$$
B d_{O}=\frac{1.6 S a+1.3 S i+1.1 C l+0.224 O M}{S a+S i+C l+O M} .
$$

A bulk density higher than the maximum for ideal plant growth indicates compaction and reduced soil porosity and pore connectivity that may restrict root growth and cause poor movement of water and air through the soil. Therefore, $P A W_{O}$ was adjusted by the ratio of optimum bulk density, $B d_{O}$, to measured bulk density, $B d$, for the final estimate of $P A W$, 


$$
P A W=P A W_{O} * \frac{B d_{O}}{B d} .
$$

\section{Comparison of PAW Algorithms}

It is beyond the scope of this manuscript to provide a comprehensive analysis of all possible methods to estimate PAW. However, four existing PAW algorithms were chosen for comparison to the newly developed BNW algorithm to demonstrate how the accuracy of the BNW algorithm compares to other commonly used techniques. The first method is a linear regression of texture and organic matter developed by Rawls, et al. (1982) and hereafter termed "Rawls" algorithm. The second method is a regression technique that includes clay activity potential developed by Baumer and Rice (1988) and termed the "MUUF" algorithm. The third method is a non-linear regression developed by Saxton and Rawls (2006), termed "SR" algorithm. The last method, termed "NN", is a nonparametric algorithm developed by Nemes, et al. (2006) in which soil water retention is estimated with a nearest neighbor classification technique.

The NN algorithm is unique because it is based on pattern recognition as opposed to fitting equations to data. The $\mathrm{NN}$ algorithm requires stored data that are only used when estimates need to be generated. For this study the stored data used for the $\mathrm{NN}$ algorithm is termed the reference dataset and is also derived from the USDA NCSS Soil Characterization Data. The reference dataset consists of all layers that remained after removal of layers with incomplete records, extreme data, and not possible or incorrectly entered data values as specified in the preceding section (NCSS, 2005). The reference dataset is not restricted to agricultural pedons; 35,253 soil layers met the criteria. Since the test dataset is a subset of this larger reference dataset, the soil layer being predicted from the test dataset was removed from the reference dataset before calculations were made.

The predicted PAW values of all five algorithms were compared relative to the measured values of PAW in the test dataset. First, the simulated versus measured PAW were graphically compared by plotting the measured versus predicted values and the corresponding density contours. Next, four 
model evaluation statistics (root mean square error (RMSE), coefficient of determination $\left(\mathrm{R}^{2}\right)$, NashSutcliffe efficiency (NSE), and Percent Bias (PBIAS)) were used to assess goodness-of-fit and accuracy of each algorithm compared to the entire test dataset by pedon (1,852 samples) and layer (10,890 samples). The RMSE is a measure of variance between the simulated and measured (or observed) values. The coefficient of determination is a measure of the colinearity between the simulated and measured data and calculated as the square of the Pearson's product-moment correlation coefficient (Everitt, 2002). The NSE is the proportion of residual variance compared to measured variance (Nash \& Sutcliffe, 1970). The PBIAS is a measure of the central tendency of the simulated data to be larger or smaller than the measured data (Gupta et al., 1999). Last, the five algorithms were analyzed by USDA texture class for goodness-of-fit, measured by $\mathrm{R}^{2}$, and accuracy, measured by PBIAS.

\section{Results and Discussion}

There is visible variation between the measured and predicted PAW values for all five algorithms for the 1,853 complete soil pedons (Fig. 1), and the 10,890 individual soil layers in the test dataset (Fig. S1). The contour lines highlight how the point density changes. Ideally, the highest density of points signified by the most concentric contour should be a narrow ellipse parallel to the gray one-toone line. The MUUF algorithm has a large portion of the highest-density points above the one-to-one line, indicating that it tends to over predict PAW by pedon and layer. For Rawls, NN, and SR algorithms the most concentric circles are in the shape of a circle instead of an ellipse, indicating that there is wider range of estimated PAW values where point density is high. Furthermore, the range of measured PAW on the $\mathrm{x}$-axis is often greater than the range of estimated values on the $\mathrm{y}$-axis. The NN, Rawls, and BNW algorithms rarely predict low PAW, less than $0.05 \mathrm{~m}^{3} \mathrm{~m}^{-3}$, and MUUF, Rawls, and $\mathrm{NN}$ algorithms rarely predict high PAW, greater than $0.22 \mathrm{~m}^{3} \mathrm{~m}^{-3}$. 


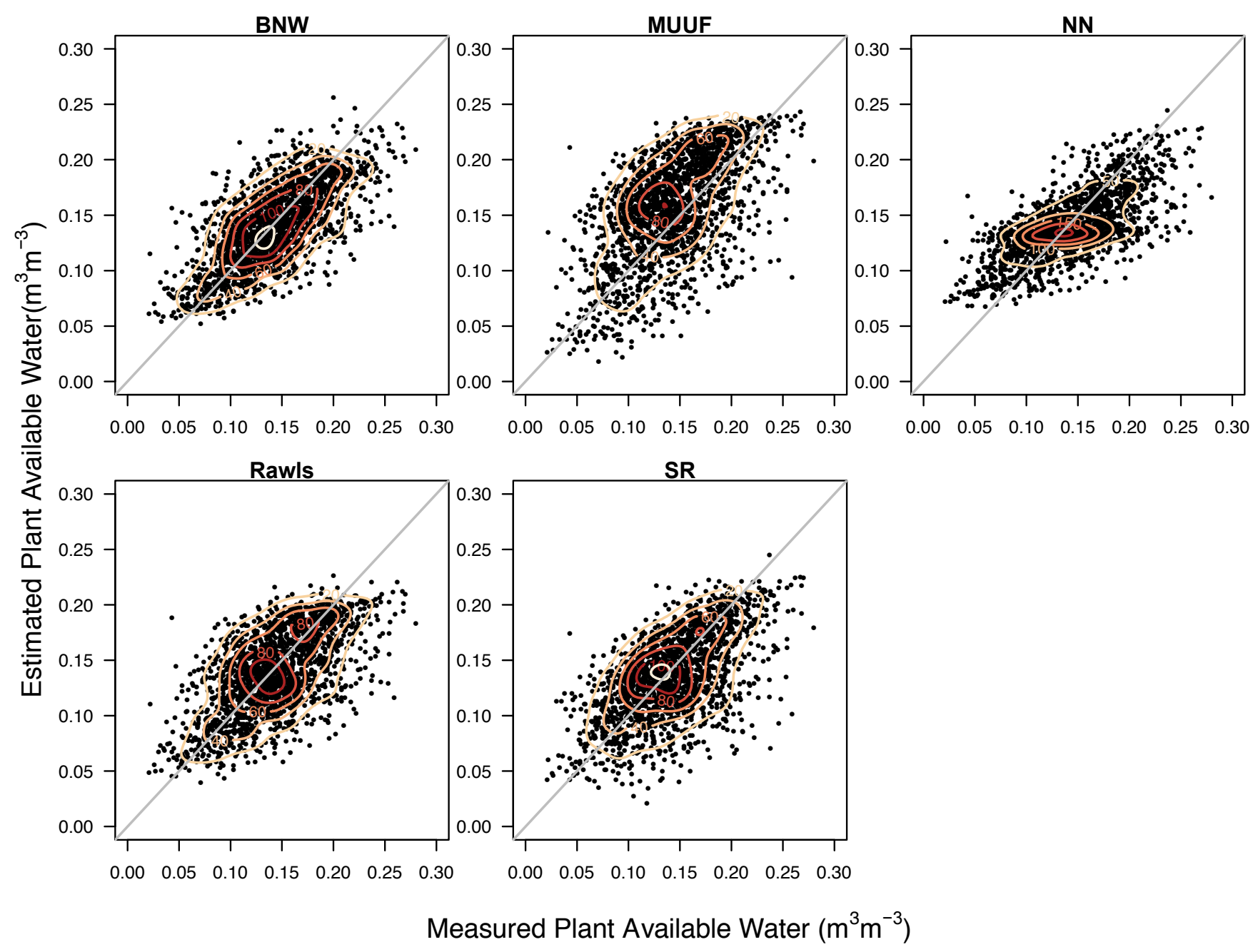

Figure 1. Measured PAW versus estimated PAW for each pedon. Contours highlight how point density changes. The gray line is the one-to-one line.

The BNW algorithm is the best performing algorithm for three of the four model evaluation statistics by pedon and layer (Table 1). The NN algorithm is the best performing algorithm for RMSE and NSE by pedon and layer. The MUUF, Rawls, and SR algorithms do not perform the best for any the model evaluation statistics analyzed by pedon or layer. The RMSE is a measure of the residual error terms. For all algorithms, the RMSE is higher for individual soil layers than complete soil pedons (Table 1). The BNW and NN algorithms performed the best with the lowest RMSE by pedon $\left(0.032 \mathrm{~m}^{3} \mathrm{~m}^{-3}\right)$ and layer $\left(0.042 \mathrm{~m}^{3} \mathrm{~m}^{-3}\right)$. The MUUF algorithm performed the worst with the highest RMSE by pedon $\left(0.044 \mathrm{~m}^{3} \mathrm{~m}^{-3}\right)$ and layer $\left(0.054 \mathrm{~m}^{3} \mathrm{~m}^{-3}\right)$. The values for RMSE calculated for this study are also within the ranges reported by other studies of PAW estimation with values ranging from 
$0.02-0.11 \mathrm{~m}^{3} \mathrm{~m}^{-3}$ (Nemes, Schaap, \& Wosten, 2003; Wosten, et al., 2001).

Table1: Model evaluation statistics summarized by pedon and layer. Bold values indicate the best performing algorithm for each statistic.

\begin{tabular}{|c|c|c|c|c|c|c|c|c|}
\hline \multirow[t]{2}{*}{ Algorithm } & \multicolumn{4}{|c|}{ Pedons $(1,853)$} & \multicolumn{4}{|c|}{ Layers $(10,890)$} \\
\hline & RMSE & $\mathrm{R}^{2}$ & NSE & PBIAS & RMSE & $\mathrm{R}^{2}$ & NSE & PBIAS \\
\hline BNW & 0.032 & 0.473 & 0.448 & -1.7 & 0.042 & 0.397 & 0.374 & -0.6 \\
\hline MUUF & 0.044 & 0.325 & -0.040 & 9.8 & 0.054 & 0.264 & 0.029 & 11.3 \\
\hline NN & 0.032 & 0.454 & 0.449 & -2.2 & 0.042 & 0.381 & 0.378 & -1.9 \\
\hline Rawls & 0.036 & 0.368 & 0.294 & -2.4 & 0.046 & 0.299 & 0.241 & -1.0 \\
\hline SR & 0.038 & 0.340 & 0.229 & -4.3 & 0.046 & 0.298 & 0.235 & -3.1 \\
\hline
\end{tabular}

We analyzed goodness-of-it for each algorithm using two statistics, coefficient of determination $\left(\mathrm{R}^{2}\right)$ and Nash-Sutcliffe efficiency (NSE). The BNW algorithm has the highest $\mathrm{R}^{2}$, explaining 47.3 percent of the variation in PAW by pedon and 39.7 percent by layer. The MUUF algorithm has the lowest $\mathrm{R}^{2}$, explaining 32.5 percent of the variation in PAW by pedon and 26.4 percent by layer. The NN has the highest NSE of 0.449 by pedon and 0.378 by layer, and the BNW algorithm has the second highest NSE of 0.448 by pedon and 0.374 by layer. The MUUF algorithm has the lowest NSE of -0.040 by pedon and 0.029 by layer. Negative NSE values indicate that the mean is a better predictor of PAW variation than the values predicted by the MUUF algorithm. Both model fit statistics, $\mathrm{R}^{2}$ and NSE, are highest for the NN and BNW methods.

The central tendency of the mean was analyzed by calculating the percent bias (PBIAS). BNW is the algorithm with the least biased mean and slightly underestimates mean PAW by 1.7 percent for pedons and by 0.6 percent for layers. The MUUF algorithm is the most positively biased algorithm and overestimates mean PAW by 9.8 percent and 11.3 percent by pedon and layer, respectively. The SR algorithm is the most negatively biased algorithm and underestimates mean PAW by 4.3 percent for pedons and by 3.1 percent for layers.

The BNW and NN were the top two performing algorithms for goodness-of-it and accuracy by pedon and layer. The BNW method is a simple calculation that does not require external data, whereas the NN algorithm is a computationally intensive and requires a relatively large reference dataset for estimation. The accuracy of the NN algorithm will depend on the quality and quantity of data 
available for the reference dataset (Nemes et al., 2006). In the study, a large reference dataset was used containing 35,253 soil layers.

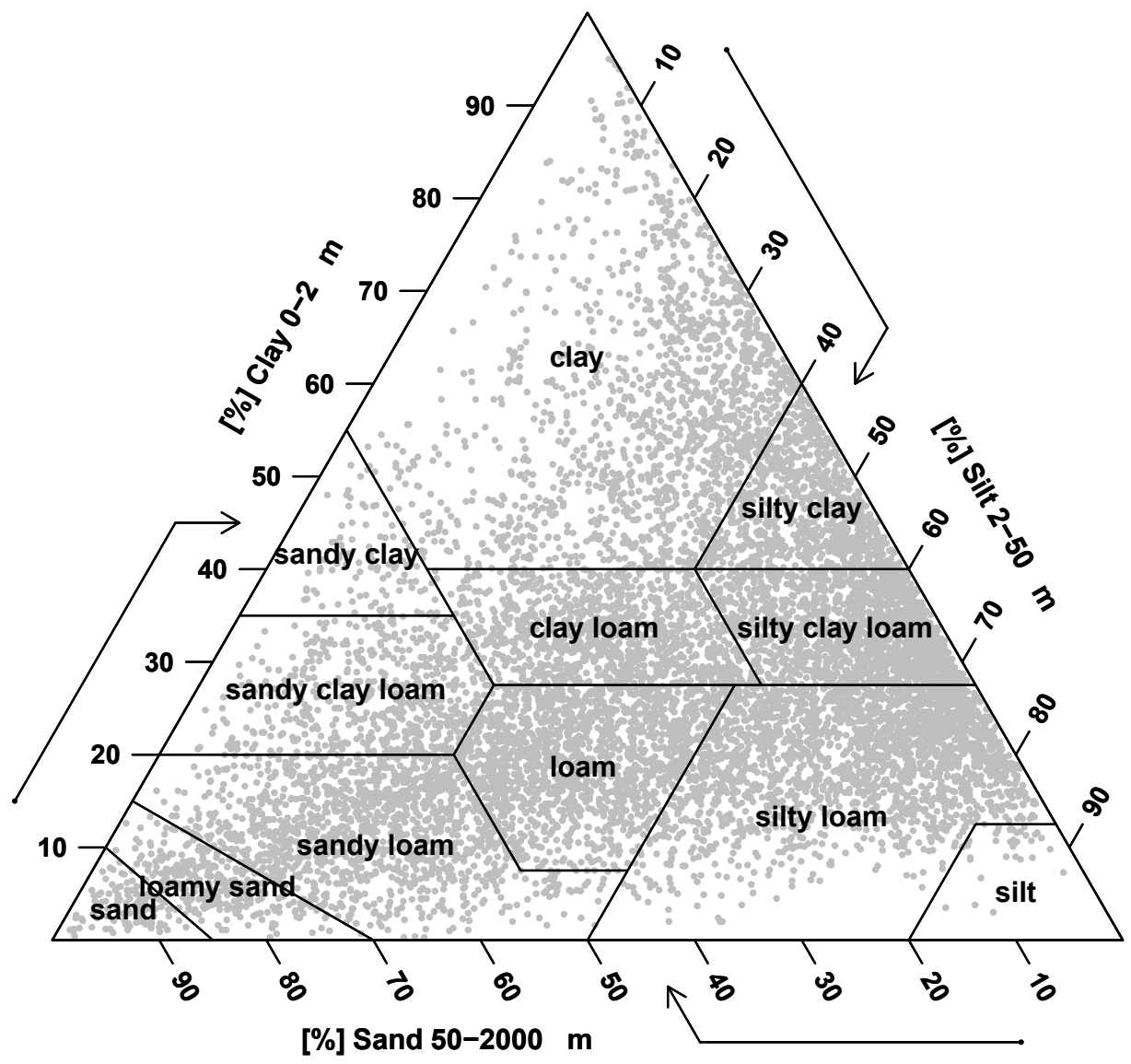

Figure 2: Each gray point is a layer in the test dataset plotted by percent sand, silt, and clay with USDA texture classes labeled.

PAW is an important variable in mechanistic modeling that directly impacts plant growth and indirectly impacts a wide range of variables, such as hydrology, water erosion, sediment loss, nutrient/pesticide fate and transport, and greenhouse gas emissions. If estimates of PAW continue being used in large-scale simulation models and in decision support tools, it is necessary to understand the accuracy of these algorithms for a wide range of agricultural soils. To this end, we analyzed the goodness-of-it $\left(\mathrm{R}^{2}\right)$ and the accuracy (PBIAS) of the five PAW algorithms for all 10,890 layers in the test dataset by USDA texture class (Fig. 2). There is a wide variety in the number of layers sampled 
from each texture class for agricultural pedons. Silt layers were sampled the least and make up only 0.3 percent of the test dataset, whereas silt loam makes up roughly 20 percent of the test dataset (Table 2). Texture classes with less than 50 samples were not analyzed because the small sample size is likely not representative of all agricultural lands.

Table 2: Mean measured PAW and mean estimated PAW for five algorithms by USDA texture class. Bold values indicate the estimated PAW algorithm closest to the measured PAW for each texture class.

\begin{tabular}{cccccccc}
\hline & Number of & \multicolumn{6}{c}{ Mean Plant Available Water $\left(\mathrm{m}^{3} \mathrm{~m}^{-3}\right)$} \\
\cline { 2 - 7 } Texture & Layers & Measured & BNW & Rawls & MUUF & SR & NN \\
\hline c & 1459 & 0.126 & $\mathbf{0 . 1 2 9}$ & 0.132 & 0.143 & 0.112 & 0.131 \\
sic & 807 & 0.134 & 0.155 & 0.166 & 0.181 & 0.143 & $\mathbf{0 . 1 3 3}$ \\
sc & 93 & 0.082 & $\mathbf{0 . 0 8 1}$ & $\mathbf{0 . 0 8 1}$ & 0.107 & 0.109 & 0.093 \\
cl & 1013 & 0.129 & 0.131 & 0.131 & 0.160 & 0.137 & $\mathbf{0 . 1 3 0}$ \\
sicl & 1562 & 0.156 & 0.174 & 0.181 & 0.208 & 0.172 & $\mathbf{0 . 1 5 4}$ \\
scl & 553 & 0.107 & 0.093 & 0.088 & $\mathbf{0 . 1 0 8}$ & 0.100 & 0.109 \\
l & 1506 & 0.145 & $\mathbf{0 . 1 3 7}$ & 0.133 & 0.154 & 0.135 & $\mathbf{0 . 1 3 7}$ \\
sil & 2232 & 0.191 & 0.185 & 0.185 & 0.211 & $\mathbf{0 . 1 8 9}$ & 0.186 \\
sl & 1275 & 0.123 & 0.105 & 0.093 & 0.092 & 0.093 & $\mathbf{0 . 1 1 4}$ \\
si & 37 & - & - & - & - & - & - \\
ls & 278 & 0.087 & 0.078 & 0.064 & 0.044 & 0.063 & $\mathbf{0 . 0 8 5}$ \\
s & 116 & 0.069 & 0.063 & 0.047 & 0.026 & 0.053 & $\mathbf{0 . 0 7 1}$ \\
\hline
\end{tabular}

Table 3: Percent bias (PBIAS) of estimated PAW for five algorithms by USDA texture class. Bold values indicate the least biased model for each texture class.

\begin{tabular}{|c|c|c|c|c|c|c|}
\hline \multirow[b]{2}{*}{ Texture } & \multirow{2}{*}{$\begin{array}{c}\text { Number of } \\
\text { Layers }\end{array}$} & \multicolumn{5}{|c|}{ Percent Bias of Estimated PAW } \\
\hline & & BNW & Rawls & MUUF & $\begin{array}{l}\text { SR } \\
\end{array}$ & NN \\
\hline $\mathrm{c}$ & 1459 & 2.5 & 4.4 & 13.8 & -11.5 & 4.1 \\
\hline sic & 807 & 15.2 & 23.3 & 34.4 & 6.2 & -1.2 \\
\hline $\mathrm{sc}$ & 93 & -1.1 & -1.5 & 30.2 & 33.5 & 14 \\
\hline $\mathrm{cl}$ & 1013 & 1.1 & 1.5 & 23.5 & 6.2 & 0.9 \\
\hline sicl & 1562 & 11.6 & 15.9 & 33.6 & 10.4 & -1.2 \\
\hline scl & 553 & -13.4 & -17.9 & 1 & -6.3 & 1.7 \\
\hline 1 & 1506 & -5.2 & -8.4 & 6.6 & -6.7 & -5.6 \\
\hline sil & 2232 & -3.2 & -3.3 & 10 & -1.5 & -2.8 \\
\hline sl & 1275 & -14.9 & -24 & -25.1 & -24.1 & -7.2 \\
\hline si & 37 & - & - & - & 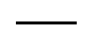 & - \\
\hline ls & 278 & -9.9 & -26.1 & -49.6 & -27.4 & -2.3 \\
\hline $\mathrm{s}$ & 116 & -8.8 & -31.2 & -62.7 & -23.8 & 3 \\
\hline
\end{tabular}

There is substantial variation in mean measured PAW by USDA texture class (Table 2). Sand holds the least PAW, $0.069 \mathrm{~m}^{3} \mathrm{~m}^{-3}$, and silt loam holds the most PAW, $0.191 \mathrm{~m}^{3} \mathrm{~m}^{-3}$. The mean estimated PAW by the NN algorithm is closest to mean measured PAW for seven of the eleven texture classes (Table 2). The mean estimated PAW by the BWN algorithm is closest for three texture classes, clay, sandy clay, and loam. PBIAS also shows a similar picture with the NN algorithm having the smallest 
percent bias for six of the eleven texture classes (Table 3), and the BNW algorithm having the smallest PBIAS for clay, sandy clay, and loam. Furthermore, the NN is the least bias algorithm across all texture classes, overestimating at most by 14.0 percent and underestimating at most by -7.2 percent. The MUUF is the most bias algorithm across all texture classes, overestimating at most by 33.5 percent and underestimating at most by -62.7 percent.

In general, most algorithms tend to underestimate mean PAW for a majority of texture classes (greater than five texture classes), except for the MUUF algorithm that overestimates mean PAW for eight texture classes. BNW, MUUF, and Rawls methods overestimate mean PAW the most on silty clay by 15.2 percent, 23.3 percent, and 34.4 percent respectively. Whereas NN and SR overestimate mean PAW the most on sandy clay by 33.5 percent and 14.0 percent, respectively. The BNW, NN, and SR underestimate mean PAW the most on sandy loam by -14.9 percent, -25.1 percent, and -24.1 percent, respectively. Rawls and MUUF underestimate mean PAW the most on sand by -23.8 percent and -62.7 percent respectively.

Table 4: Coefficient of determination of measured PAW and estimated PAW for five algorithms by USDA texture. Bold values indicate the top performing model for each texture class.

\begin{tabular}{ccccccc}
\hline & Number of & \multicolumn{5}{c}{ Coefficient of Determination of Estimated PAW } \\
\cline { 2 - 7 } Texture & Layers & BNW & Rawls & MUUF & SR & NN \\
\hline c & 1459 & $\mathbf{0 . 1 9 3}$ & 0.045 & 0.025 & $<0.001$ & 0.060 \\
sic & 807 & $\mathbf{0 . 2 0 0}$ & 0.007 & 0.001 & 0.002 & 0.003 \\
sc & 93 & $\mathbf{0 . 3 2 0}$ & 0.087 & 0.118 & 0.006 & 0.170 \\
cl & 1013 & $\mathbf{0 . 1 8 2}$ & 0.028 & 0.031 & 0.016 & 0.024 \\
sicl & 1562 & $\mathbf{0 . 2 5 3}$ & 0.075 & 0.112 & 0.079 & 0.125 \\
scl & 553 & $\mathbf{0 . 2 7 9}$ & 0.182 & 0.185 & 0.095 & 0.154 \\
1 & 1506 & $\mathbf{0 . 1 4 8}$ & 0.060 & 0.035 & 0.034 & 0.078 \\
sil & 2232 & 0.123 & 0.118 & 0.085 & 0.120 & $\mathbf{0 . 1 8 1}$ \\
sl & 1275 & $\mathbf{0 . 2 7 7}$ & 0.225 & 0.174 & 0.168 & 0.206 \\
si & 37 & $\overline{\mathbf{0 . 0 8 3}}$ & -0.051 & 0.042 & 0.029 & 0.044 \\
1s & 278 & $\mathbf{0 . 0 4 8}$ & 0.001 & 0.001 & $<0.001$ & 0.033 \\
s & 116 & $\mathbf{0 . 0 4 8}$
\end{tabular}

The BNW algorithm has the highest coefficient of determination for 10 out of the 11 texture classes with sufficient data (Table 4). BNW explains more than 20 percent of the variation in measured PAW 
for sandy clay, silty clay, sandy loam, silty clay loam, and sandy clay loam. BNW model fit varies by texture class explaining the least variation in measured PAW, five percent, for sand, and the most variation in measured PAW, 32 percent, for sandy clay. Furthermore, all models explain less than ten percent of the variation in measured PAW for sand and loamy sand where PAW is low, less than 0.1 $\mathrm{m}^{3} \mathrm{~m}^{-3}$. Similar to any other laboratory measurement, there is error associated with measurements of the volume of water released when the soil is dried from $1 / 3$ bar to 15 bars water tension. Sandy soils, in particular, have a low water holding capacity and may be difficult to accurately measure (USDANRCS, 2005). These soils may have amorphous mineral coatings of iron and aluminum contributing to PAW proportionally higher than with finer textured soils.

The BNW algorithm explains the most overall variation in measured PAW and the most variation in measured PAW by texture class compared to all other commonly used algorithms. However, a majority of the variation in measured PAW remains unexplained for all texture classes. This new method was developed based on the central concept of estimating the optimum bulk density and plant available water based on values for percent sand, silt, clay, and organic matter. The current implementation of the algorithm does not address sub-fractions of particle size or mineralogy (including amorphous phase), which are known to affect water holding capacity. Future research may incorporate more detailed information on sub-fractions of particle size and/or mineralogy into the optimum equations for bulk density and plant available water.

The BNW methods presented here is designed and tested to estimate PAW for soils that have agricultural disturbance. Furthermore, we excluded soils with high bulk density (greater than $2.0 \mathrm{~g} \mathrm{~m}^{-}$ ${ }^{3}$ ) and low bulk density, less than $0.8 \mathrm{~g} \mathrm{~m}^{-3}$, high organic carbon (greater than 5.75 percent), and volcanic soils. These values were removed because they are extreme and not typical of agricultural soils. The application of the BNW algorithm to other land uses and extreme soils needs to be tested.

The BNW algorithm presented here is not a complete pedotransfer function that can estimate all values of the water-retention curve (Baumer \& Rice, 1988; Rawls \& Brakensiek, 1989). The BNW 
algorithm only estimates PAW, an important hydraulic parameter for simulation modeling typically calculated as the difference between the volume of water released when soil is dried at 1/3 bar and 15 bar water tension. For some simulation models, the estimation of additional hydraulic parameters may be necessary.

\section{Conclusions}

This study presents a new algorithm for to estimate PAW based on commonly measured soil properties: bulk density, particle size distribution, and organic matter. The new BNW algorithm outperformed several commonly used algorithms for accuracy and model fit by pedon and layer and by USDA texture class. The BNW algorithm has the best fit and accuracy on sandy clay and sandy clay loam soils. The BNW algorithm tends to under predict PAW on sandy loam soils and over predicts PAW on silty clay soils. The BNW model explains the least variation in measured PAW on sand soils and sandy loam soils.

If estimations of PAW continue being used in large-scale simulation models and in decision support tools, it is necessary that these estimates are accurate for a wide range of soil types. Otherwise, important variation in soil type and soil properties that impact PAW may not be directly and indirectly reflected in simulation modeling results. Incorporation of the BNW algorithm into process based simulation models will improve the accuracy of crop production estimates and environmental impacts at regional and national scales.

\section{Acknowlegements}

We appreciate helpful comments from Mari-Vaughn V. Johnson, Javier Osorio Leyton, and Daren Harmel. The USDA is an equal opportunity employer. 


\section{References}

Arnold, J. G., Harmel, R. D., Johnson, M. V., Bingner, R., Strickland, T. C., Walbridge, M., . . Wang, X. (2014). Impact of the Agricultural Research Service Watershed Assessment Studies on the Conservation Effects Assessment Project Cropland National Assessment. Journal of soil and water conservation, 69(5), 137-144.

Arnold, J. G., Srinivasan, R., Muttiah, R. S., \& Williams, J. R. (1998). Large Area Hydrologic Modeling and Assessment Part I: Model Development 1. Journal of the American Water Resources Association, 34(1), 73-89.

Baumer, O., \& Rice, J. (1988). Methods to predict soil input data for drainmod. American Society of Agricultural Engineers (Microfiche collection) (USA).

Becker, R. A., Chambers, J. M., \& Wilks, A. R. (1988). The NewS Language. A Programming Environment for Data Analysis and Graphics. 702 pp, Wadsworth and Brooks/Cole: Advanced Books and Software, Pacific Grove, CA, USA.

Behrman, K. D., Kiniry, J. R., Winchell, M., Juenger, T. E., \& Keitt, T. H. (2013). Spatial forecasting of switchgrass productivity under current and future climate change scenarios. Ecological Applications, 23(1), 73-85.

Everitt, B. S. (2002). The Cambridge Dictionary of Statistics: Cambridge University Press, Cambridge, UK.

Gelfand, I., Sahajpal, R., Zhang, X., Izaurralde, R. C., Gross, K. L., \& Robertson, G. P. (2013). Sustainable bioenergy production from marginal lands in the US Midwest. Nature, 493(7433), 514-517.

Gijsman, A. J., Jagtap, S. S., \& Jones, J. W. (2002). Wading through a swamp of complete confusion: how to choose a method for estimating soil water retention parameters for crop models. European Journal of Agronomy, 18(12), $77-106$.

Jagtap, S. S., Lall, U., Jones, J. W., Gijsman, A. J., \& Ritchie, J. T. (2004). Dynamic nearest-neighbor method for estimating soil water parameters. Transactions of the ASAE, 47(5), 1437-1444.

Jones, J. W., Tsuji, G. Y., Hoogenboom, G., Hunt, L. A., Thornton, P. K., Wilkens, P. W., . . Singh, U. (1998). Decision support system for agrotechnology transfer: DSSAT v3. In G. Y. Tsuji, G. Hoogenboom \& P. K. Thornton (Eds.), Understanding Options for Agricultural Production (pp. 157-177): Springer Netherlands.

Kiniry, J. R., Williams, J. R., Gassmann, P. W., \& Debaeke, P. (1992). General, process-oriented model for two competing plant species. Transactions of the ASAE, 35(3), 801-810.

Nash, J. E., \& Sutcliffe, J. V. (1970). River flow forecasting through conceptual models part I: A discussion of principles. Journal of Hydrology, 10(3), 282-290.

NCSS. (2005). National Cooperative Soil Characterization Database. http://ncsslabdatamart.sc.egov.usda.gov 
Nemes, A., Rawls, W. J., \& Pachepsky, Y. A. (2006). Use of the Nonparametric Nearest Neighbor Approach to Estimate Soil Hydraulic Properties. Soil Science Society of America Journal, 70(2), 327-336.

Nemes, A., Schaap, M. G., \& Wosten, J. H. M. (2003). Functional Evaluation of Pedotransfer Functions Derived from Different Scales of Data Collection. Soil Science Society of America Journal, 67(4), 1093-1102.

Nemes, A., Timlin, D. J., Pachepsky, Y. A., \& Rawls, W. J. (2009). Evaluation of the Pedotransfer Functions for their Applicability at the U.S. National Scale. Soil Science Society of America Journal, 73(5), 1638-1645.

Parton, W. J., Hartman, M., Ojima, D., \& Schimel, D. (1998). DAYCENT and its land surface submodel: description and testing. Global and Planetary Change, 19(1), 35-48.

Powers, S. E., Ascough, J. C., Nelson, R. G., \& Larocque, G. R. (2011). Modeling water and soil quality environmental impacts associated with bioenergy crop production and biomass removal in the Midwest USA. Ecological Modelling, 222(14), 2430-2447.

Ratliff, L. F., Ritchie, J. T., \& Cassel, D. K. (1983). Field-Measured Limits of Soil Water Availability as Related to Laboratory-Measured Properties1. Soil Science Society of America Journal, 47(4), 770-775.

Rawls, W. J., \& Brakensiek, D. L. (1989). Estimation of Soil Water Retention and Hydraulic Properties. In H. J. MorelSeytoux (Ed.), Unsaturated Flow in Hydrologic Modeling (pp. 275-300): Springer Netherlands.

Rawls, W. J., Brakensiek, D. L., \& Saxton, K. E. (1982). Estimation of soil water properties. Trans. ASAE, 25(5), 13161320.

Ritchie, J. T., Ratliff, L. F., \& Cassel, D. K. (1987). Soil laboratory data, field descriptions and field measured soil water limits for some soils of the United States. ARS Technical Bulletin, 276.

Saxton, K. E., \& Rawls, W. J. (2006). Soil Water Characteristic Estimates by Texture and Organic Matter for Hydrologic Solutions. Soil Science Society of America Journal, 70(5), 1569-1578.

Saxton, K. E., Rawls, W. J., Romberger, J. S., \& Papendick, R. I. (1986). Estimating Generalized Soil-water Characteristics from Texture1. Soil Science Society of America Journal, 50(4), 1031-1036.

Schaap, M. G., Leij, F. J., \& van Genuchten, M. (1998). Neural Network Analysis for Hierarchical Prediction of Soil Hydraulic Properties. Soil Science Society of America Journal, 62(4), 847-855.

Schaffer, J. P. (1995). Multiple Hypothesis Testing. Ann. Rev. Psych, 46, 561-584.

Stockle, C. O., Martin, S. A., \& Campbell, G. S. (1994). CropSyst, a cropping systems simulation model: Water/nitrogen budgets and crop yield. Agricultural Systems, 46(3), 335-359.

Timlin, D. J., Pachepsky, Y. A., Acock, B., \& Whisler, F. (1996). Indirect estimation of soil hydraulic properties to predict soybean yield using GLYCIM. Agricultural Systems, 52(2), 331-353. 
Tuppad, P., Santhi, C., Wang, X., Williams, J. R., Srinivasan, R., \& Gowda, P. H. (2010). Simulation of conservation practices using the APEX model. Applied engineering in agriculture, 26(5), 779-794.

U.S. Department of Agriculture, N. R. C. S. (1995). National soil survey handbook.

USDA-NRCS. (2005). National Soil Survey Handbook, title 430-V1. Soil Properties and Quantiles (Part 618).

Williams, J. R., Arnold, J. G., Srinivasan, R., \& Ramanarayanan, T. S. (1998). APEX: A New Tool for Predicting the Effects of Climate and CO2 Changes on Erosion and Water Quality. In J. Boardman \& D. Favis-Mortlock (Eds.), Modelling Soil Erosion by Water (pp. 441-449): Springer Berlin Heidelberg.

Williams, J. R., Jones, C. A., Kiniry, J. R., \& Spanel, D. A. (1989). The EPIC crop growth model. Trans. ASAE, 32(2), 497-511.

Wosten, J. H. M., Pachepsky, Y. A., \& Rawls, W. J. (2001). Pedotransfer functions: bridging the gap between available basic soil data and missing soil hydraulic characteristics. Journal of Hydrology, 251(3,4), 123-150. 


\section{Appendix}

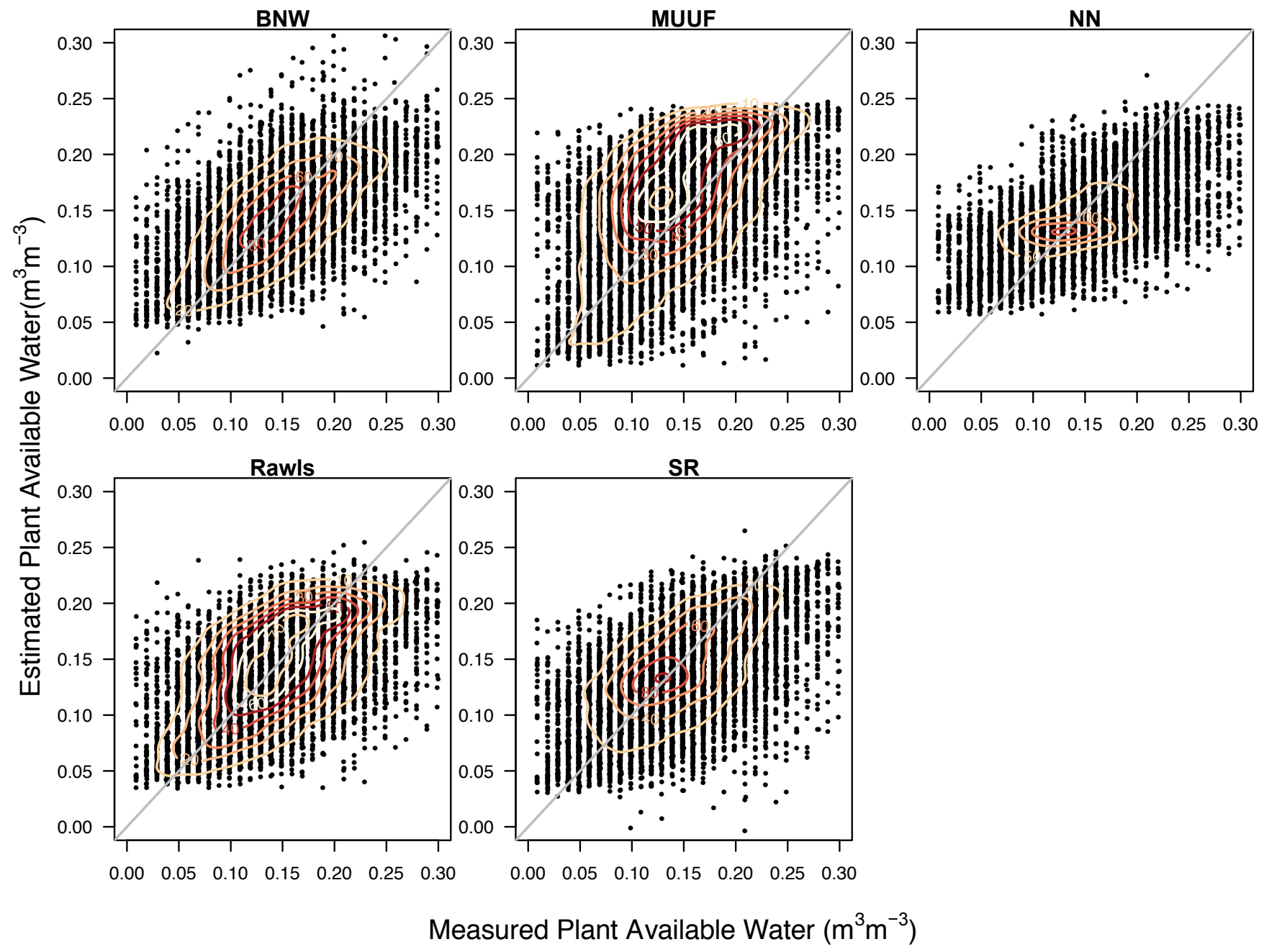

Figure S1. Measured PAW versus estimated PAW for each soil layer. Contours show how the density of points changes. The gray line is the one-to-one line. 